\section{Aerodynamics Department}

The Aerodynamics Department was found to be in a state of considerable activity and expansion. In a $4 \mathrm{ft}$. tunnel the measurement of the flutter deriva. tives on an aerofoil is effected by imparting an oscillatory motion to the aerofoil via a nickel tube, and recording the driving torque by an electrical method which depends on the change of permeability of nickel with stress. A systematic investigation of such oscillating forces is in hand, in the first instance on aerofoils. A small water tunnel has been constructed for observing the nature of the transition from laminar to turbulent flow. An ultra-microscope enables the flow to be observed in detail by rendering visible extremoly minute particles in the water.

The overall stability characteristics of a model aeroplane are being studied by observing its be. haviour in a wind tunnel when supported with a restricted number of degrees of freedom. If this method can be doveloped to a satisfactory state, it has the great advantage that experiments of this kind can be made in any ordinary wind tunnel and do not demand special apparatus. The measurement of gusts has been made for some time on high towers, but this is obviously limited to certain sites and altitudes. A gust recorder which has been designed for attachment to the cable of a kite balloon was exhibited. This will enable a much more extensive exploration of gusts to be made. Difficulties connected with the movement of the supporting cable have yet to be overcome, howover.

\section{William Froude Laboratory}

In the William Froude Laboratory, tests of a model hull fitted with propeller, shafting and internal driving motor were boing made in the Yarrow tank. The method of obtaining the propulsive efficiency and the interaction between the hull and the pro. peller were explained. In the new tank, rolling tests were being made on a model under way, and the effect of various keel and hull shapes on the decrement of the roll was demonstrated. Research on the pre. vention of cavitation is in progress in this Department, and in the propeller tunnel this phenomenon was exhibited, using stroboscopic illumination con. trolled from the propeller shaft.

\title{
INTERNAL STRAINS IN SOLIDS
}

\begin{abstract}
A CONFERENCE on "Internal Strains in Solids" was held at Bristol on July 11-13 under the joint auspices of the Physical Society and the University of Bristol. Of the large number of subjects discussed, it will only be possible to mention a ferw here. Most of the papers presented to the conference will be published in a special number of the Proceedings of the Physical Society which it is hoped will appear next autumn.
\end{abstract}

There was a discussion on the naturo of slip in metal crystals. While there was by no means general agreement, the following picture of the process would perhaps find a certain number of supporters :

Slip takes place through the passage through the crystal of 'dislocations', in the sense in which the word is used in the theories of G. I. Taylor, Orowan and Polanyi. The dislocation theory pictures a perfect crystal as an elastic modium having the theoretical yield point and no plastic properties; the theoretical yield point is the stress required to pull one plane of atoms over the next all at once, and is many thousands of times higher than the yield points of hard metals. According to the theory, however, if the crystal contains any dislocations at all-and in practice it always does-the crystal will have a very much lower yield point, becauso the dislocations can move easily through the crystal.

The rate at which a crystal will yield under stress may be determined, according to Orowan, by one of two factors: (1) the rate at which now dislocations are formed; (2) the rate at which they move under the external stress. Orowan believes that in general the second factor is the important one, and that the yield point is the stress at which the dislocations move fast enough to give observable slip.

As regards the origin of the dislocations, it is believed that they are formed at special spots in the crystal where the stress is particularly high. Thus irregularities in the crystal have two roles: to make possible the formation of dislocations, and to hinder their motion. Thus if (1) determine the resistance to glide, irregularities may soften the material, and if (2) determine it, irregularities may harden it. Orowan gives evidence to show that both cases may occur in practice.

It was suggested that glide starts by the formation and motion in a given erystallographic direction of a dislocation of atomic dimensions; but that as soon as the stress reaches the point at which a dislocation can move at all rapidly, the heat developed would cause a dislocation of much larger order of magnitude, giving the macroscopic slip bands observed.

As regards the factors resisting the motion of a dislocation, Peierls' paper shows that a finite stress is required to move a dislocation even in a perfect crystal; thus (in contradiction to G. I. Taylor's hypothesis) a perfect crystal containing just ono dislocation should have a finite if small resistance to shear at a low enough temperature.

The much greater resistance to the motion of a dislocation in an age- or work-hardened material must be due to deviations from the ideal lattice. Two hypotheses are possible: (1) that the dislocations are stopped at surfaces of misfit between crystallites; (2) that the motion of dislocations is impeded by the presence of internal strains. (G. I. Taylor's theory makes use of both hypotheses. The dislocations are supposed to be stopped by surfaces of misfit in the lattice; but this does not lead to any resistance to shear, because it is assumed that new dislocations can always be formed at surfaces. The hardening comes from the fact that the strain around the stuck dislocations prevents new dislocations from moving.) If $\sigma_{0}$ is the internal shear stress at any point in the lattice, the directions of $\sigma_{0}$ will be random. Thus at some points along the length of a dislocation the dislocation will be pushed one way, at other points in another; and for the 
dislocation to move in a definite direction, the external stress $\sigma$ must bo greater than $\sigma_{0}$ at all points along the dislocation. Hence the observed yield point should be of the order of the mean value of $\sigma_{0}$.

There was a discussion of tho mechanism of precipitation of one phase from another, and of the cause of precipitation hardening. Prof. $R$. Becker emphasized that in alloys in which the degree of supersaturation is small, the time taken to form a nucleus will be long, because a small nucleus will be unstable owing to surface tension, and will usually evaporate before it can grow to a size at which it will be stable. Thus on cooling an alloy, the precipitation is not so rapid on first entering the two-phase region as at a lower temperature where the degree of supersaturation will be greater; and this is so in spite of the very rapid drop in the diffusion rate as the temperature is lowered (cf. R. Becker, Ann. Phys., 32,128 ; 1937).

The distinction was emphasized between precipitates which have broken away from the parent lattice and form a new phase, and the smaller nuclei or 'knots' which are formed in the parent lattice, without breaking away. A thermodynamical equilibrium is possiblo between such knots and the original solid solution, and probably oxists in duralumin.

In cases where the two phases have widely differing lattice parameters, it may be impossible for a stable nucleus of one phase to form in the lattice of the other, without breaking away; the energy required to expand or compress the nuclous is too great, so that precipitation would lead to an increase in the free energy. Thus any stable nucleus must already have broken away from the parent lattice. It was suggested, however, that the strain energy would be less if the nuclei assumed a plate-like shape; and that this might be the cause of the segregation of copper atoms on the (100) planes of the aluminium lattice observed by Proston in single crystals of copper aluminium alloys.

Prof. W. L. Bragg described a theory of the structure of a cold-worked metal. The boundaries between the crystallites of a metal must in general be mobile at room temperature; it was. suggested that these boundaries are not frozen in position but are in dynamical equilibrium undor their surface tensions. Thermal fluctuations will cause these boundaries to wave about, and will lead to the gradual disappearance of the smaller crystallites. Thus if a metal is thrown into an amorphous state by cold-working, it will rapidly self-anneal up to a certain coarseness of crystallite size, characteristic of the temperature, beyond which point crystallite growth should be very slow. According to these ideas, no truly amorphous stato is possiblo in a metal.
N. F. II.

\section{POPULATION PROBLEMS OF HOUSING ESTATES}

A CHARACTERISTIC of the admirable series of studies issued by the Social Science Department of the University of Liverpool* is their attempt to foresee the problems which social and economic tendencies are presenting to-day and to indicate measures which might be taken either to solve them as they arise or to prevent them becoming too intractable. The latest addition to the New Merseysido Series is no exception. In this survey of the population problems of new estates, with special reference to Norris Green, Mr. Norman Williams indicates the difficulties caused in such districts by a failure in human understanding, together with a serious lack of co-ordination between the different departments of the local authority in the early stages of development. In regard to the provision of schools, for example, the survey reveals grave weaknesses in our present system of local government, an entirely new area with entirely new problems being administered by numerous departments, out of touch with the estate, often acting independently and sometimes in opposition to each other.

The acute problem of school accommodation in Norris Green resulted directly from the policy of the Housing Committee, but it was left to the Education Committeo to solve. Mr. Williams indicates some of the serious consequences of this lack of foresight and co-ordination : the exclusion of children from infants' schools until they were considerably boyond the normal age ; the very frequent transference of pupils from one department to a higher; the unusually large classes (up to fifty-six), first in the junior schools and then in the senior schools. Accompanied by

* University of Liverpool: Social Science Department, Statistics Dirision. Population Problems of New Estates, with Special Reference to Norris Green. Pp. 52. (Liverpool: University Press of Liverpool, 1939.) 18. net. these features has been a steady decline in number of children seoking admission, which has resulted in a steady decrease in the mean age of admission into infants' schools, and it is anticipated that within two or three years sufficient spare room will be available in most infants' schools in Norris Green for the organization of nursery classes.

Mr. Williams, however, is not content with directing attention to the mistakes of the past and the disastrous consequences of lack of accommodation and large classes for a fow children. He is equally concerned with the future. The figures he quotes indicato that the big fall in school population will be accompanied by a big rise in the supply of juvenile labour, and since the local demand for labour shows no signs of increasing, a big increase in unemployment is to be expected amongst boys and girls. It is pointed out that among male adults, unemployment rose from 9 per cent in 1930 to 22 per cent in 1937, the actual increase in numbers being 550. In 1937 there woro about 1,200 unmarried men of more than nineteen in Norris Green, a figure which is expected to increase to 1,500 by 1942 and 2,100 in 1947. The chances of these men obtaining employment are not encouraging and there is the prospect of about 1,400 of them being unemployed in 1942 .

Transport provides another example of a problem created by the Housing Department and left to another Corporation Department to solve. The amount of work in tho locality is limited and the extra workers, if thoy obtain employment, must find it at a distance and will need conveyance. It is doubtful whether the present extended sorvices meet the need, and by 1947 it is possible there will bo an increase of moro than 50 per cent in those using the combined bus and tram services. 